\title{
NOTICIAS
}

\section{El doctor Jong Wook Lee, nuevo Director General de la Organización Mundial de la Salud}

Para ser ratificado formalmente por los 192 miembros de la Asamblea Mundial de la Salud como próximo Director General de la Organización Mundial de la Salud (OMS), fue nominado el sudcoreano doctor Jong Wook Lee. En la selección final del candidato a presidir la OMS también fueron considerados los doctores Peter Piot, Director Ejecutivo de ONUSIDA; Ismail Sallan, Ministro de Salud de Egipto; Pascoal Mocumbi, Primer Ministro de Mozambique, y JulioFrenk Mora, Secretario de Salud de México.

El doctor Lee estudió en el Colegio de Medicina de la Universidad de Seúl, y en la Universidad de Hawaii. Se vinculó a la OMS en 1983 como Consultor del Programa de Control de la Lepra en el Pacífico Sur. De 1986 a 1990 fue Consultor Regional para Enfermedades Crónicas. Luego, hasta 1994, fue Director de Prevención y Control de Enfermedades, en la Región del Pacífico Occidental, con sede en Manila. A partir de 1994, fue trasladado a Ginebra como Director del Programa Global de Vacunas. Al momento de su elección como Director General, Lee era la cabeza del Programa de Tuberculosis.

Consideró su nominación como "Un verdadero privilegio y un gran honor...", y planteó que la visión de la OMS debe centrarse en un llamado al mundo para efectuar grandes esfuerzos dirigidos a mejorar la salud individual, la de las comunidades y la de las naciones, desarrollando estrategias para intervenciones específicas en salud, en áreas prioritarias. Dichas estrategias deben estar destinadas a producir beneficios en salud tangibles y mensurables. Esta visión de la OMS le permitirá a la institución exhibir las siguientes cinco características:

1. Altamente efectiva;

2. eficiente;

3. significativamente descentralizada;

4. claramente responsable financiera, profesional y administrativamente; $y$

5. ser una gran plaza laboral que atraiga a la gente más brillante, más tenaz y enérgica, para la cual la Organización brinde un ambiente y una cultura que les permita hacer las mayores contribuciones en cada una de sus áreas de desempeño.

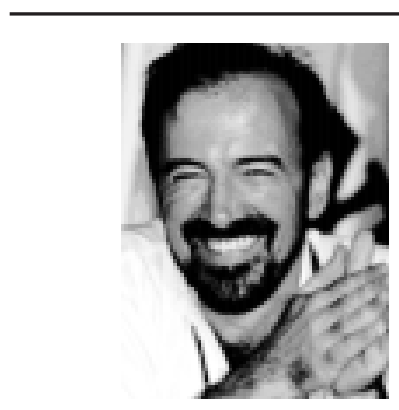

\section{Sensible fallecimiento del doctor Juan Luis Londoño de la Cuesta}

En el mes de febrero de este año, en cumplimiento de sus actividades como Ministro de Protección Social de Colombia, falleció el doctor Juan Luis Londoño de la Cuesta, sin duda uno de los grandes innovadores de las reformas de los sistemas de salud de América Latina. De éstas, una de las más importantes ha sido la adelantada en su país, la cual sería inconcebible sin su decidida participación.

Juan Luis Londoño estudió Administración de Negocios y economía en las universidades EAFIT y de Antioquia, en Medellín, Maestría en Política Económica en la Universidad de los Andes, en Bogotá, y Maestría y Doctorado en Economía, en la Universidad de Harvard, en los Estados Unidos de América. 